\title{
Endothelial function in migraine: a cross-sectional study
}

\author{
Floris H Vanmolkot ${ }^{1 *}$, Jan N de Hoon ${ }^{2}$
}

\begin{abstract}
Background: Migraine has been associated with cardiovascular disorders. Endothelial dysfunction may be a mechanism underlying this association. The present study tested the hypothesis that endothelium-dependent vasodilation, basal endothelial nitric oxide release and endothelial fibrinolytic capacity are impaired in migraine patients.

Methods: Graded doses of sodium nitroprusside (SNP, 0.2 to $0.8 \mu \mathrm{g} \cdot \mathrm{min}^{-1} \cdot \mathrm{dL}^{-1}$ forearm), substance $\mathrm{P}$ (0.2 to 0.8 pmol.min ${ }^{-1} \cdot \mathrm{dL}^{-1}$ forearm) and $\mathrm{N}^{\mathrm{G}}$-monomethyl-L-arginine (L-NMMA, 0.1 to $0.4 \mu \mathrm{mol} \cdot \mathrm{min}^{-1} \cdot \mathrm{dL}^{-1}$ forearm) were infused into the brachial artery of 16 migraine patients with or without aura during a headache-free interval and 16 ageand sex-matched subjects without a history of migraine. Forearm blood flow (FBF) was measured by strain-gauge venous occlusion plethysmography. Local forearm release of tissue plasminogen activator (t-PA) in response to substance $P$ infusion was assessed using the arteriovenous plasma concentration gradient. Responses to infused drugs were compared between patients and matched controls by analysis of variance.

Results: In both migraine patients and control subjects, SNP and substance P caused a dose-dependent increase, and L-NMMA a dose-dependent decrease in FBF ( $P<0.001$ for all responses). In both groups, substance $P$ caused an increase in t-PA release $(P<0.001)$. FBF responses and t-PA release were comparable between migraine patients and control subjects.

Conclusions: The absence of differences in endothelium-dependent vasodilation, basal endothelial nitric oxide production and stimulated t-PA release between migraine patients and healthy control subjects argues against the presence of endothelial dysfunction in forearm resistance vessels of migraine patients.
\end{abstract}

\section{Background}

Migraine is a common neurovascular disorder, characterized by recurrent episodes of headache, dysfunction of the autonomic nervous system, and in some patients, an aura involving neurologic symptoms [1]. The pathophysiology of migraine is largely unknown. During the last decade, a neurogenic hypothesis of migraine has largely replaced the classical vascular theory [2]. Nonetheless, migraine has been associated with several cardiovascular disorders including ischemic stroke [3], ischemic heart disease [4], vasospastic disorders $[5,6]$ and genetically determined vasculopathies [7].

The mechanisms underlying the association between migraine and cardiovascular disorders are currently

\footnotetext{
*Correspondence: floris.vanmolkot@mumc.nl

'Department of Internal Medicine, Maastricht University Medical Center, P.

Debyelaan 25, 6202 AZ Maastricht, The Netherlands

Full list of author information is available at the end of the article
}

unknown. Migraine has been proposed as an "endotheliopathy" [8]. The vascular endothelium regulates numerous vascular functions [9]. In response to specific stimuli, endothelial cells secrete local vaso-active mediators, including the vasodilator nitric oxide (NO) and vasoconstrictor endothelin-1 (ET-1) and tissue-type plasminogen activator ( $t-P A)$, which contributes to the fibrinolytic pathway. Several observations suggest that endothelial function is abnormal is migraine patients, including an increased prevalence of anti-endothelial cell antibodies that may induce endothelial damage [10] and raised plasma levels of ET-1 [11] and von Willebrand factor [12]. Interestingly, ET-1 has been shown to produce cortical spreading depression (CSD) in rats [13]. CSD is considered the biological substrate of the migraine aura and a trigger for migraine attacks [2]. Although evidence from human studies is currently

\section{Biomed Central}


lacking, these observations suggest that an endothelial factor may induce a migraine attack.

The aim of the present study was to test the hypothesis that migraine is associated with endothelial dysfunction. To this end, endothelial function was assessed in vivo in the human forearm resistance vasculature by measuring: (1) stimulated endothelial NO release, (2) basal endothelial NO release and (3) stimulated endothelial t-PA release.

\section{Methods}

\section{Subjects}

Migraine patients with or without aura, as defined by the International Headache Society diagnostic criteria [14] and control subjects were recruited from hospital and university staff, university students and the general population through advertisements. Major exclusion criteria were: age $<18$ and $\geq 50$ years, body mass index $(\mathrm{BMI})<18$ and $\geq 30 \mathrm{~kg} \cdot \mathrm{m}^{-2}$, history of cardiovascular disease, smoking, hypertension (systolic blood pressure $>140 \mathrm{~mm} \mathrm{Hg}$ or diastolic blood pressure $>90 \mathrm{~mm} \mathrm{Hg}$ ), diabetes, hypercholesterolaemia (total cholesterol $>6.5$ $\mathrm{mmol} / \mathrm{L}$ ), pregnancy or lactation and regular use of vasoactive drugs (except hormonal contraceptives). Based on medical history, physical examination, routine laboratory tests and electrocardiography all participants were in good health.

The diagnosis of migraine, initially made by a neurologist or general physician, was confirmed by a validated questionnaire [15]. Patients with a history of migraine of $<1$ year, $>15$ days of headache per month or using antimigraine drugs $>10$ days/month were excluded. Control subjects without a history of migraine were matched for gender, age and hormonal contraceptive use. Control subjects with on average $>1$ headache episode per month, a history of moderate or severe headaches or first-degree relatives with a history of migraine were excluded.

The study was approved by the ethical committee of the University Hospital and conducted in accordance with the Declaration of Helsinki. All subjects provided written informed consent prior to participation.

\section{Experimental conditions}

Experiments were performed in the morning after an overnight fast in a quiet, temperature controlled (23 \pm $1^{\circ} \mathrm{C}$ ) room. Female subjects were studied on day 5-12 of their menstrual cycle (mid follicular phase) or outside the "pill free" period if taking oral contraceptives. Subjects abstained from any drug (except oral contraceptives) for at least 3 days and from alcohol- and caffeinecontaining beverages for at least 24 hours. During the experimental visit, subjects rested supine on a comfortable bed. Migraine patients were headache free for at least 72 hours. If a migraine attack ensued within 24 hours after the visit, measurements were repeated in another headache-free period.

\section{Intra-arterial drug infusion}

A catheter (Angiocath ${ }^{\circ}$ 22G, Beckton Dickinson, Temse, Belgium) was introduced into the brachial artery of the non-dominant arm after local anaesthesia with $1 \mathrm{~mL}$ of lidocaine (Xylocaine ${ }^{\bullet}, 10 \mathrm{mg} / \mathrm{mL}$, Astra Pharmaceuticals, Brussels, Belgium). Drugs or saline $(\mathrm{NaCl} 0.9 \%)$ were infused continuously in a single blind manner using automated infusion pumps (Ivac ${ }^{\bullet}$ P1000, Ivac Medical Systems, Eli Lily, Brussel, Belgium) and pressure-resistant polyethylene infusion tubes (Original-Perfusor ${ }^{\circ}, \mathrm{B}$ Braun, Melsungen, Germany). Doses were normalised to forearm volume (measured by water displacement) by maintaining the total rate of intra-arterial infusions constant at $100 \mu \mathrm{L} \cdot \mathrm{min}^{-1} \cdot \mathrm{dL}^{-1}$ forearm.

\section{Drugs}

Sodium nitroprusside (SNP, David Bull Laboratories, Warwick, United Kingdom), substance P (Clinalfa, Läufelfingen, Switzerland) and $\mathrm{N}^{\mathrm{G}}$-monomethyl-L-arginine (L-NMMA, Clinalfa, Läufelfingen, Switzerland) were dissolved in $\mathrm{NaCl}$ 0.9\% (B Braun, Melsungen, Germany) on the day of the experiment and kept at $4{ }^{\circ} \mathrm{C}$. SNP solutions were protected from light during the experiment. Doses were selected based on previous work $[16,17]$.

\section{Forearm blood flow and blood pressure}

Forearm blood flow (FBF) was assessed in both the infused and non-infused arm using strain-gauge venous occlusion plethysmography [18]. Electrically calibrated mercury-insilastic strain gauges (D.E. Hokanson, Bellevue, USA) were applied at the point of maximal forearm circumference. The hands were occluded from the circulation during measurements through rapid inflation of wrist cuffs to 200 $\mathrm{mmHg}$. Wrist cuffs were inflated at least $60 \mathrm{~s}$ before starting plethysmographic recordings in order to allow FBF to stabilize. Upper arm cuffs were intermittently inflated to $40 \mathrm{mmHg}$ for the first $10 \mathrm{~s}$ in every $15 \mathrm{~s}$ to block temporarily venous return of blood from the forearm and thus obtain multiple plethysmographic tracings (EC6 Plethysmograph, D.E. Hokanson, Bellevue, USA). Analogue voltage output from the plethysmograph was processed by an analogue-to-digital converter (Powerlab\%/8SP, AD Instruments, Castle Hill, Australia) and appropriate software (Chart ${ }^{\circ}$ v4.0 for Windows, AD Instruments, Castle Hill, Australia) and recorded onto a computer (Dell Optiplex ${ }^{\circ}$ G1, Dell Computer Corporation, Limerick, Ireland). Calibration was achieved using the internal standard of the plethysmograph.

Systolic and diastolic blood pressure and heart rate were measured in the non-infused arm using a validated 
semi-automated oscillometric device (OMRON 705IT, OMRON Healthcare, Hoofddorp, The Netherlands). Measurements were performed immediately after the preceding FBF recording (Figure 1).

\section{Blood sampling and assay}

Arterial and venous blood samples were obtained at the end of substance $P$ infusions and the preceding saline infusion (Figure 1). For venous blood sampling, a catheter (20 or $22 \mathrm{G}$, Insyte-W, Beckton Dickinson, Temse, Belgium) was inserted into a superficial antecubital vein of the infused arm. Arterial blood was sampled through the arterial catheter. Blood $(4.5 \mathrm{~mL})$ was collected into icecooled glass tubes containing $0.5 \mathrm{~mL} 0.105 \mathrm{M}$ sodium citrate (BD Vacutainer, Beckton Dickinson, Plymouth, UK) and kept on ice before being centrifuged at $2500 \mathrm{~g}$ for 15 min at $4^{\circ} \mathrm{C}$ within 1 hour of sampling. Plasma was transferred to plastic tubes (CryoTube ${ }^{\circ}$, Nunc A/S, Roskilde, Denmark) and stored at $-80^{\circ} \mathrm{C}$ until analysis. Plasma t-PA concentration was determined using an enzymelinked immunosorbent assay as previously described [19].

\section{Study protocol (Figure 1)}

After arterial cannulation, saline was infused for $30 \mathrm{~min}$ to allow for equilibration. At the end of this infusion, two FBF measurements (3 min each), were performed. The mean of these was used as baseline FBF. Three incremental doses of each drug (SNP at 0.2, 0.4 and 0.8 $\mu \mathrm{g} \cdot \mathrm{min}^{-1} \cdot \mathrm{dL}^{-1}$ forearm; Substance $\mathrm{P}$ at $0.2,0.4$ and 0.8 pmol.min ${ }^{-1} \cdot \mathrm{dL}^{-1}$ forearm; and L-NMMA at $0.1,0.2$ and $0.4 \mu \mathrm{mol} . \mathrm{min}^{-1} \cdot \mathrm{dL}^{-1}$ forearm) were infused for $6 \mathrm{~min}$ at each dose, separated by at least $12 \mathrm{~min}$ of saline infusion between the different drugs (wash-out). FBF was measured during the final 3 min of each drug infusion or wash-out infusion period. The order of drug infusions was the same for all subjects.

\section{Data analysis and statistics}

FBF was determined from the slope of the initial part of each plethysmographic tracing. Plethysmographic data were extracted from Chart data files and FBF responses were calculated for individual plethysmographic tracings using a template spreadsheet (Microsoft Excel 2000 v9.0, Microsoft Corporation, USA). Tracings unsuitable for analysis due to motion artefacts were manually rejected. All tracings were analysed by the same analyst who was unaware of the subject's diagnosis. The mean of the final $5 \mathrm{FBF}$ tracings from each recording period was used for analysis. The FBF measurement at the end of the saline infusion preceding each drug infusion was used as baseline measurement for that particular drug infusion. FBF responses were expressed as absolute FBF in $\mathrm{ml} \cdot \mathrm{min}^{-1} \cdot \mathrm{dL}^{-1}$ forearm for SNP and Substance P and as percentage change from baseline in the FBF-ratio between infused and non-infused arm for L-NMMA, as discussed previously [20].

As an estimate of local t-PA release, the product of the arteriovenous plasma concentration gradient and forearm plasma flow was calculated: release $=\left(C_{v}-C_{a}\right) \times F B F \times$ [(101-hematocrit)/100], where $C_{v}$ and $C_{a}$ are the venous and arterial plasma concentrations, respectively [21].

Comparison of baseline characteristics between groups was made by $t$-test for independent samples. FBF responses, blood pressure and heart rate were analysed by repeated measures analysis of variance (ANOVA), with dose as within subject variable. Comparisons between groups were made by repeated measures ANOVA, with dose as within subject variable and group (migraine or control) as between subject variable. As a summary measure, the mean difference in FBF response between groups, expressed as change in FBF from baseline to the highest infused dose, was calculated together with the $95 \%$ confidence interval (CI). Based on power calculations using data from previous work [22], the population size of the present study gives $80 \%$ power at a significance level of 0.05 for detecting a $29 \%$ difference in FBF increase between groups in response to the highest dose of Substance P.

All statistical analyses were performed using commercially available software (NCSS 2000, Number Cruncher

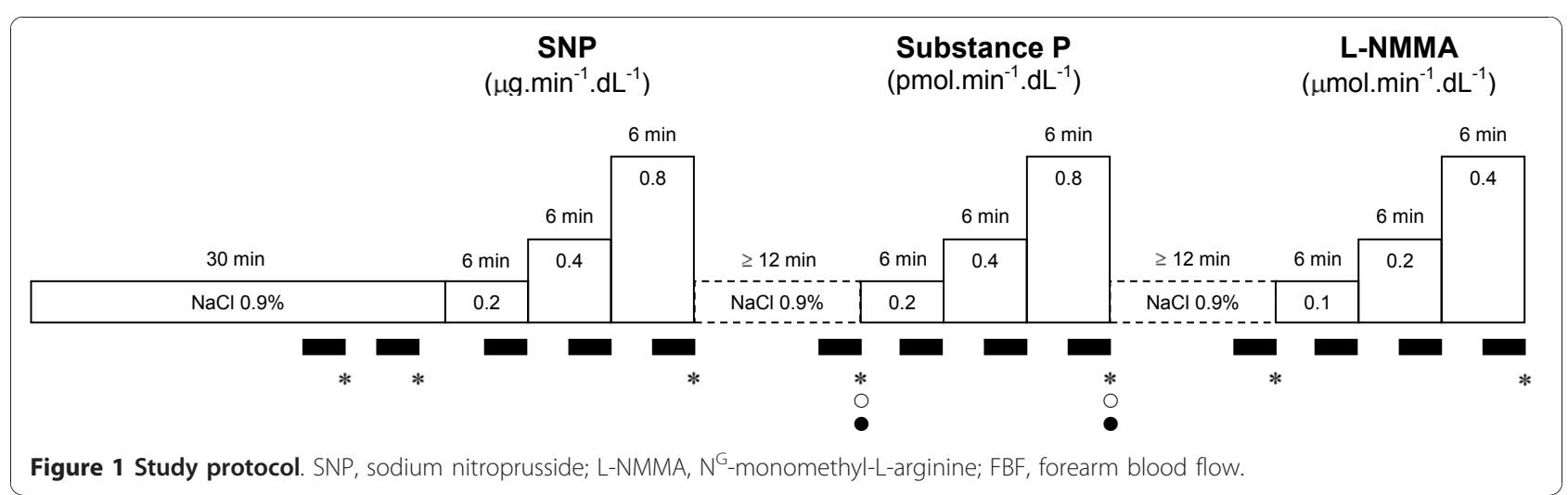


Statistical Systems, Kaysville, USA). $P<0.05$ was considered statistically significant. Data are presented as mean \pm SEM in figures and mean \pm SD in tables and text.

\section{Results}

No differences in baseline characteristics were observed between groups (Table 1). Migraine patients had been suffering from migraine for $5.6 \pm 3.3$ years. Migraine with aura was diagnosed in 9 (56\%) and migraine without aura in 7 (44\%) patients. Migraine attacks occurred with a frequency of $1.2 \pm 0.9$ per month and lasted $20 \pm$ 11 hours. As acute anti-migraine drugs, analgesics (paracetamol or non-steroidal anti-inflammatory drugs) were used by $75 \%$, triptans by $13 \%$ and metoclopramide by $6 \%$ of patients.

Blood pressure, heart rate and FBF in the non-infused arm did not change during the infusions (data on file; Table 2).

SNP and Substance P increased FBF in a dose-dependent fashion (Table 2, Figure 2). The FBF responses to SNP and Substance $P$ were comparable between migraine patients and controls $(P=0.44$ and $P=0.80$, respectively). The mean differences in FBF response to SNP and Substance $\mathrm{P}$ were $1,8 \mathrm{ml} \cdot \mathrm{min}^{-1} \cdot \mathrm{dL}^{-1}$ forearm (95\% CI, -2.5 to 6.1 ) and $-0,6 \mathrm{ml} \cdot \mathrm{min}^{-1} \cdot \mathrm{dL}^{-1}$ forearm (95\% CI -2.8 to 1.6 ), respectively.

L-NMMA decreased FBF in a dose-dependent fashion (Table 2, Figure 3). The FBF response to L-NMMA was comparable between migraine patients and controls $(P=$ $0.50)$. The mean difference in FBF response to $\mathrm{L}$ NMMA was $2 \%$ (95\% CI, -10 to 13 ).

Venous plasma t-PA levels did not differ between migraine patients and controls $\left(7,4 \pm 11 \mathrm{ng} \cdot \mathrm{mL}^{-1}\right.$ and $6,5 \pm$ 5.4 ng. $\mathrm{mL}^{-1}$, respectively, $\left.P=0.86\right)$. The basal and stimulated t-PA release were comparable $(P=0.69$ and $P=$ 0.87 , respectively) between migraine patients $(-0.6 \pm 1.1$
ng.dL ${ }^{-1} \cdot \mathrm{min}^{-1}$ and $\left.7.4 \pm 5.5 \mathrm{ng} \cdot \mathrm{dL}^{-1} \cdot \mathrm{min}^{-1}\right)$ and controls $\left(-0.6 \pm 2.1 \mathrm{ng} \cdot \mathrm{dL}^{-1} \cdot \mathrm{min}^{-1}\right.$ and $\left.7.1 \pm 5.5 \mathrm{ng} \cdot \mathrm{dL}^{-1} \cdot \mathrm{min}^{-1}\right)$.

Subgroup analyses did not reveal differences between migraine patients with aura and without aura (data not shown).

\section{Discussion}

In the present study, we compared FBF responses to SNP, Substance P and L-NMMA between migraine patients with or without aura and matched individuals without migraine. In addition, we compared the acute $t$ PA release in response to substance P in both groups. Our findings indicate that several markers of endothelial function, including the stimulated and basal endothelial $\mathrm{NO}$ release and stimulated endothelial t-PA release, are not altered in migraine patients in between migraine attacks.

Endogenous NO is generated by the conversion of the amino acid L-arginine to citrulline by three different nitric oxide synthases (NOS). Neuronal and endothelial NOS are constitutively expressed and produce relatively small quantities of $\mathrm{NO}$ in comparison with the inducible form of the synthase. Endothelial-derived NO is a key molecule in vasomotor function. To our knowledge, this is the first study that assessed the basal endothelial release of NO in migraine patients, using a non-selective antagonist of nitric oxide synthase (L-NMMA). The response to L-NMMA did not differ between patients with migraine and control subjects, indicating that the basal endothelial release of NO from peripheral resistance vessels is unaltered in migraine patients, at least outside the migraine attack period. This does not exclude that basal NO release from other vascular beds is altered in the same patients, or that it is impaired preceding, during or immediately after a migraine attack. Previous studies measuring metabolites of $\mathrm{NO}$ in

Table 1 Baseline subject characteristics

\begin{tabular}{|c|c|c|c|}
\hline Characteristic & $\begin{array}{l}\text { Control subjects } \\
(n=16)\end{array}$ & $\begin{array}{l}\text { Migraine patients } \\
(n=16)\end{array}$ & $P$ \\
\hline Age, years & $24.0 \pm 3.0$ & $24.5 \pm 4.0$ & 0.68 \\
\hline Female, n (\%) & $12(75)$ & $12(75)$ & 1.0 \\
\hline Current hormonal contraceptive use, n (\% of women) & $10(83)$ & $10(83)$ & 1.0 \\
\hline Body mass index, $\mathrm{kg} / \mathrm{m}^{2}$ & $22.6 \pm 2.7$ & $22.7 \pm 2.3$ & 0.92 \\
\hline Systolic blood pressure, $\mathrm{mm} \mathrm{Hg}$ & $119 \pm 8$ & $117 \pm 9$ & 0.47 \\
\hline Diastolic blood pressure, $\mathrm{mm} \mathrm{Hg}$ & $70 \pm 5$ & $70 \pm 7$ & 0.93 \\
\hline Heart rate, bpm & $61 \pm 10$ & $64 \pm 9$ & 0.29 \\
\hline Total cholesterol, mmol/L & $4.0 \pm 0.8$ & $4.1 \pm 0.5$ & 0.72 \\
\hline $\mathrm{HDL}$ cholesterol, mmol/L & $1.8 \pm 0.4$ & $1.7 \pm 0.4$ & 0.80 \\
\hline LDL cholesterol, mmol/L & $1.9 \pm 0.6$ & $1.9 \pm 0.6$ & 0.78 \\
\hline Triglycerides, mmol/L & $0.8 \pm 0.2$ & $0.9 \pm 0.4$ & 0.27 \\
\hline Glucose, mmol/L & $4.4 \pm 0.2$ & $4.5 \pm 0.3$ & 0.81 \\
\hline Forearm volume, $\mathrm{mL}$ & $919 \pm 146$ & $855 \pm 154$ & 0.24 \\
\hline
\end{tabular}


Table 2 Forearm blood flow

\begin{tabular}{|c|c|c|c|c|c|c|c|c|}
\hline \multirow[b]{2}{*}{ Sodium nitroprusside dose, $\mu \mathrm{g} \cdot \mathrm{min}^{-1} \cdot \mathrm{dL}^{-1}$ forearm } & \multicolumn{4}{|c|}{ Control subjects $(n=16)$} & \multicolumn{4}{|c|}{ Migraine patients $(n=16)$} \\
\hline & 0 & 0.2 & 0.4 & 0.8 & 0 & 0.2 & 0.4 & 0.8 \\
\hline non-infused arm & $2.0 \pm 0.9$ & $1.9 \pm 0.7$ & $1.8 \pm 0.8$ & $1.8 \pm 0.8$ & $2.0 \pm 0.5$ & $2.0 \pm 0.6$ & $2.1 \pm 0.8$ & $1.9 \pm 0.6$ \\
\hline infused arm & $2.0 \pm 0.5$ & $8.6 \pm 3.5$ & $10.9 \pm 4.2$ & $14.5 \pm 5.9^{*}$ & $2.1 \pm 0.5$ & $8.7 \pm 2.9$ & $12.1 \pm 4.6$ & $16.5 \pm 6.2^{*}$ \\
\hline Substance $P$ dose, pmol.min ${ }^{-1} \cdot d L^{-1}$ forearm & 0 & 0.2 & 0.4 & 0.8 & 0 & 0.2 & 0.4 & 0.8 \\
\hline non-infused arm & $1.8 \pm 0.8$ & $1.8 \pm 0.7$ & $1.8 \pm 0.7$ & $1.9 \pm 0.8$ & $2.0 \pm 0.6$ & $1.9 \pm 0.6$ & $2.1 \pm 0.6$ & $2.0 \pm 0.6$ \\
\hline infused arm & $2.2 \pm 0.7$ & $5.5 \pm 2.2$ & $6.9 \pm 2.5$ & $8.7 \pm 3.8^{*}$ & $2.5 \pm 0.7$ & $5.1 \pm 1.2$ & $6.5 \pm 1.8$ & $8.4 \pm 2.5^{*}$ \\
\hline L-NMMA dose, $\mu$ mol.min ${ }^{-1} \cdot d L^{-1}$ forearm & 0 & 0.1 & 0.2 & 0.4 & 0 & 0.1 & 0.2 & 0.4 \\
\hline non-infused arm & $1.7 \pm 0.5$ & $1.8 \pm 0.7$ & $1.9 \pm 0.9$ & $1.9 \pm 0.8$ & $2.1 \pm 0.5$ & $1.9 \pm 0.6$ & $2.1 \pm 0.6$ & $2.4 \pm 0.8$ \\
\hline infused arm & $2.0 \pm 0.5$ & $1.7 \pm 0.4$ & $1.6 \pm 0.4$ & $1.4 \pm 0.4^{*}$ & $2.5 \pm 0.6$ & $2.0 \pm 0.5$ & $1.9 \pm 0.6$ & $1.9 \pm 0.6^{*}$ \\
\hline
\end{tabular}

Data are expressed as absolute blood flows $\left(\mathrm{ml} \cdot \mathrm{min}^{-1} \cdot \mathrm{dL}^{-1}\right.$ forearm); ${ }^{*} P<0.001$ (ANOVA)

platelets or plasma during a headache free interval suggested a basal hyperactivity of the L-arginine-NO pathway [23-25]. Our findings suggest that, if basal NO production is indeed increased in migraine patients, other NO synthases than endothelial NOS in extracranial vessels are implicated.

$\mathrm{NO}$ induces vasodilation through a direct action on the vascular smooth muscle cell. A recent study in patients with migraine without aura, showed an impaired FBF response to the NO donor SNP, leading the authors to the hypothesis that vascular smooth muscle cell function is impaired in migraine without aura [26]. In contrast to these findings, we observed a comparable vasodilator response to SNP between patients with migraine and controls, which is in agreement with a previous, smaller study by our group [27]. A small study in patients with migraine without aura also showed a normal response to SNP of the cutaneous microcirculation measured by laser Doppler flowmetry [28]. Adding more complexity are findings from previous work in patients with migraine without aura showing an increased vasodilator response to another $\mathrm{NO}$ donor, nitroglycerin, of the brachial artery [29] or intracranial blood vessels [30], suggesting an arterial hypersensitivity to NO. Thus, existing data are clearly inconsistent, which may be explained by differences in patient characteristics (longstanding migraine or migraine of recent onset; migraine with or without aura) or differences in the vascular beds studied (micro- or macrovascular beds, conduit or resistance arteries; intracranial or extracranial arteries).

Several studies have evaluated endothelial function in patients with migraine. The present study confirms the findings of a previous, smaller study by our group $(\mathrm{n}=$ 10,1 patient with aura) that showed no difference in FBF response to serotonin, which releases NO through
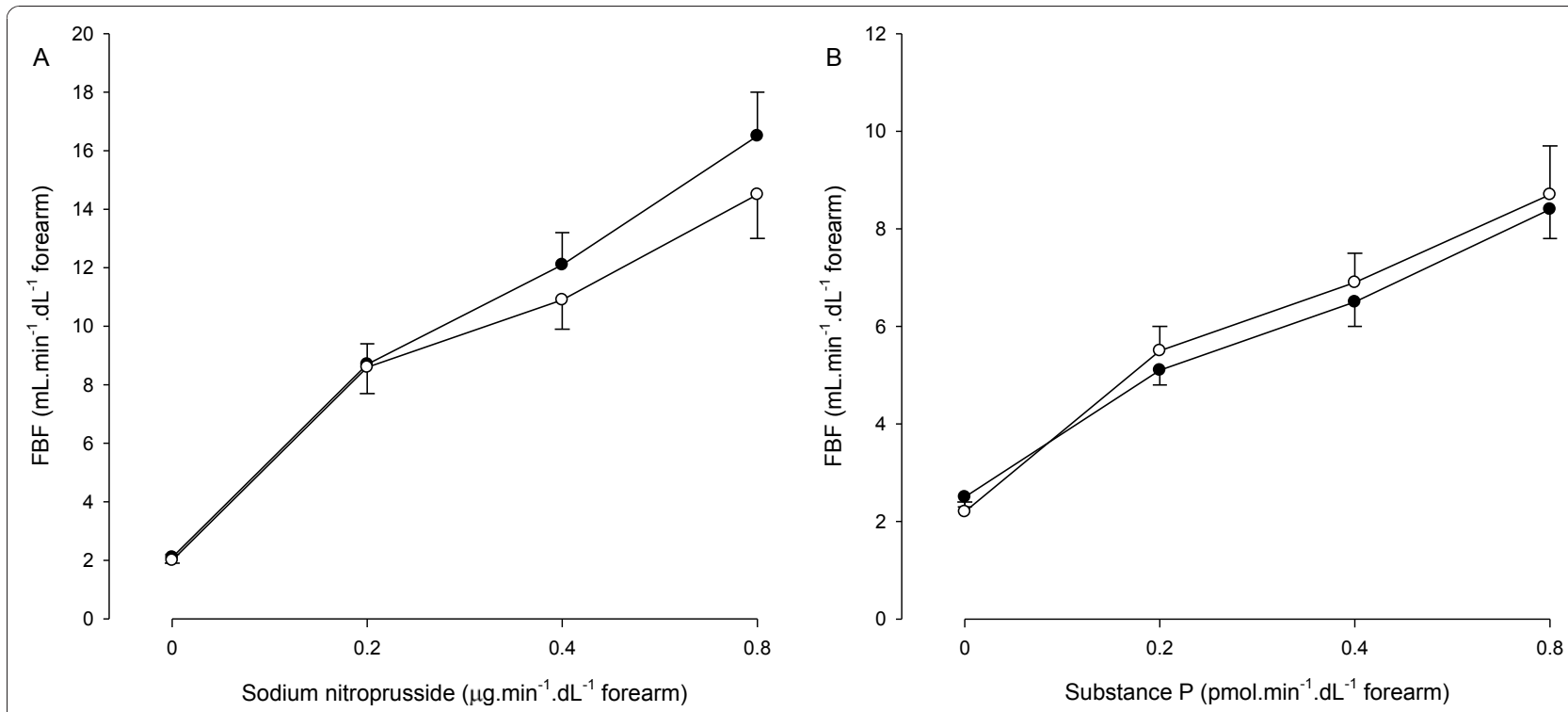

Figure 2 Forearm blood flow (FBF) response to sodium nitroprusside (A) and substance $\mathrm{P}(\mathrm{B})$ in migraine patients (closed circles) and control subjects (open circles). $P<0.001$ for all responses. 


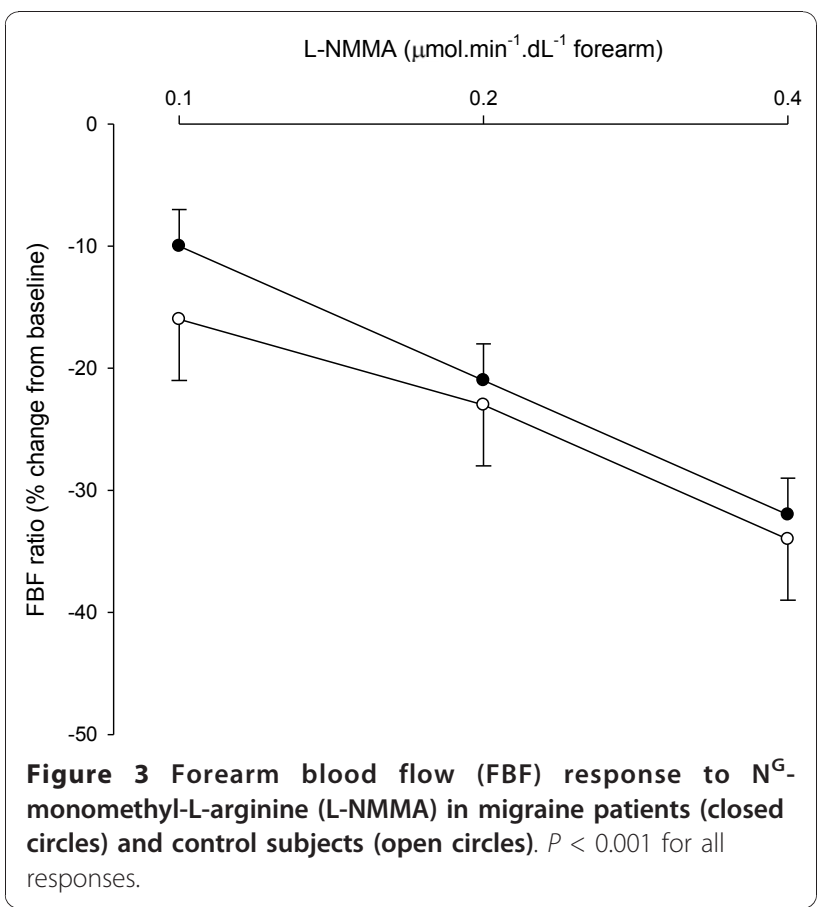

endothelial receptors [27]. A recent study in patients with migraine without aura $(n=12)$ assessed endothelial-dependent vasodilation by measuring FBF responses to acetylcholine [26]. Compared to healthy controls, FBF response to acetylcholine was impaired, but as FBF response to SNP, i.e endothelial-independent vasodilation, was impaired while acetylcholine-induced release of NO was intact, the authors hypothesized that vascular smooth muscle cell, but not endothelial cell function is impaired in migraine without aura. A small study in patients diagnosed with migraine without aura $(\mathrm{n}=9)$ showed a normal dermal blood flow response to acetylcholine measured by laser Doppler flowmetry [28]. Two small studies $(\mathrm{n} \leq 10)$ did not observe a difference in flow-mediated dilation (FMD), a measure of endothelium-dependent vasodilation, between patients and controls [27,31]. However, these studies were likely underpowered, considering the large variability of FMD measurements [32]. Recently, a larger study $(n=45)$ and a smaller follow-up study $(\mathrm{n}=24)$ observed a decreased brachial FMD in patients without aura $[29,33]$. An impaired FMD was also shown by our group in a group of patients with migraine with or without aura of recent onset $(n=50)$ [34]. In contrast, a study in patients with migraine with and without aura $(\mathrm{n}=$ 50) did not find a difference in FMD between patients with migraine and controls and between patients with migraine with aura $(\mathrm{n}=25)$ and without aura $(\mathrm{n}=25)$ [35]. Taken together, results are clearly inconsistent. The discrepancies between studies may be related to heterogeneity in study population, differences in vascular beds studied and differences in applied endothelial stimulus.

Previous work in patients with migraine suggested abnormalities of haemostasis, including abnormal platelet function, antiphospholipid antibodies and congenital thrombophilia, which may cause increased thrombotic risk in these patients [36]. The endogenous fibrinolytic system and, in particular, the acute release of t-PA from the endothelium protects the circulation from intravascular thrombosis. We assessed the acute fibrinolytic capacity of the endothelium by stimulating the endothelial release of t-PA using intra-arterial infusion of substance $P$ [21]. No difference was observed in the forearm t-PA release between migraine patients and control subjects, suggesting that endothelial fibrinolytic capacity is normal in migraine patients during a headache-free interval. A larger cross-sectional study observed an increased plasma t-PA concentration in young women with $(\mathrm{n}=61)$ and without $(\mathrm{n}=64)$ aura compared to control subjects [37].

The present study has several limitations. First, because of the invasive nature of the forearm model, a relatively small number of subjects was included. In addition, the FBF response to Substance P in the present study was 2 times lower than expected from previous work [22] on which power calculations were based. Therefore, it cannot be excluded that the present study was insufficiently powered to detect small, but clinically relevant differences between migraine patients and control subjects, in particular between migraine subgroups. Interestingly, recent prospective studies suggest that patients with migraine with aura, but not without aura, are at increased risk for cardiovascular events $[4,38]$. Therefore, additional studies in migraine subpopulations with sufficient power are needed. Second, although the forearm model serves as a convenient model for studying endothelial function, measurement of coronary and cerebrovascular endothelial function is likely to be of greatest clinical relevance, as the forearm vascular bed is less susceptible to atherosclerosis and subsequent thrombosis. Nevertheless, consistent findings between the peripheral and coronary circulation support the notion that the forearm model is a reasonable surrogate [39]. Studies comparing endothelial function in cerebral and peripheral vascular beds in the same patients are lacking. Third, endothelial fibrinolytic capacity depends on the balance between endothelial release of t-PA and plasminogen activator inhibitor type 1 (PAI-1) [21]. As no measurements of PAI-1 or t-PA activity were performed in our study, we cannot completely rule out an impaired endothelial fibrinolytic activity in patients with migraine. Finally, regarding the hypothesis of an endothelial trigger for a migraine attack, we cannot 
exclude the existence of a local endothelial dysfunction in the cranial circulation.

\section{Conclusions}

In conclusion, the absence of differences in endothelium-dependent vasodilation, basal endothelial nitric oxide production and stimulated t-PA release between migraine patients and healthy control subjects argues against the presence of endothelial dysfunction in forearm resistance vessels of migraine patients.

\section{List of Abbreviations}

CSD: cortical spreading depression; ET-1: endothelin-1; FBF: forearm blood flow; FMD: flow-mediated dilation; L-NMMA: $N^{G}$-monomethyl-L-arginine; NO: nitric oxide; NOS: nitric oxide synthase; SBP: systolic blood pressure; SNP: sodium nitroprusside; t-PA: tissue plasminogen activator

\section{Acknowledgements}

We are indebted to Dr. Jef Arnout and Marleen Van Russelt (Center for molecular and vascular biology, K.U. Leuven, Leuven, Belgium) for expertly performing the plasma t-PA determinations.

\section{Author details}

'Department of Internal Medicine, Maastricht University Medical Center, P. Debyelaan 25, 6202 AZ Maastricht, The Netherlands. ${ }^{2}$ Center for Clinical Pharmacology, University Hospital Leuven, Leuven, Belgium.

\section{Authors' contributions}

FV participated in the design of the study, conducted all experiments, performed the statistical analyses and drafted the manuscript. JdH conceived of the study, participated in its design and helped to draft the manuscript Both authors read and approved the final manuscript.

\section{Competing interests}

The authors declare that they have no competing interests.

Received: 1 September 2010 Accepted: 1 December 2010 Published: 1 December 2010

\section{References}

1. Silberstein SD: Migraine. Lancet 2004, 363:381-391.

2. Pietrobon D, Striessnig J: Neurobiology of migraine. Nat Rev Neurosci 2003, 4:386-398.

3. Bousser MG, Welch KM: Relation between migraine and stroke. Lancet Neurol 2005, 4:533-542

4. Kurth T, Gaziano JM, Cook NR, Logroscino G, Diener HC, Buring JE: Migraine and risk of cardiovascular disease in women. JAMA 2006, 296:283-291.

5. Miller D, Waters DD, Warnica W, Szlachcic J, Kreeft J, Theroux P: Is variant angina the coronary manifestation of a generalized vasospastic disorder? N Engl J Med 1981, 304:763-766

6. O'Keeffe ST, Tsapatsaris NP, Beetham WP Jr: Increased prevalence of migraine and chest pain in patients with primary Raynaud disease. Ann Intern Med 1992, 116:985-989.

7. Stam AH, Haan J, van den Maagdenberg AM, Ferrari MD, Terwindt GM: Migraine and genetic and acquired vasculopathies. Cephalalgia 2009, 29:1006-1017.

8. Appenzeller O: Pathogenesis of migraine. Med Clin North Am 1991, 75:763-789.

9. Landmesser U, Hornig B, Drexler H: Endothelial function: a critical determinant in atherosclerosis? Circulation 2004, 109:|127-33.

10. Gabrielli M, Santarelli L, Addolorato G, Foschi G, Di Gampli C, Gasbarrini A Fiore G, Cristiana DC: High prevalence of antiendothelial cell antibodies in migraine. Headache 2002, 42:385-386.
11. Gallai V, Sarchielli P, Firenze C, Trequattrini A, Paciaroni M, Usai F, Palumbo R: Endothelin 1 in migraine and tension-type headache. Acta Neurol Scand 1994, 89:47-55.

12. Tietjen GE, Al-Qasmi MM, Athanas K, Dafer RM, Khuder SA: Increased von Willebrand factor in migraine. Neurology 2001, 57:334-336.

13. Dreier JP, Kleeberg J, Petzold G, Priller J, Windmuller O, Orzechowski HD, Lindauer U, Heinemann U, Einhaupl KM, Dirnagl U: Endothelin-1 potently induces Leao's cortical spreading depression in vivo in the rat: a model for an endothelial trigger of migrainous aura? Brain 2002, 125:102-112.

14. The International Classification of Headache Disorders: 2nd edition. Cephalalgia 2004, 24(Suppl 1):9-160.

15. Tom T, Brody M, Valabhji A, Turner L, Molgaard C, Rothrock J: Validation of a new instrument for determining migraine prevalence: the UCSD Migraine Questionnaire. Neurology 1994, 44:925-928.

16. Newby DE, Wright RA, Ludlam CA, Fox KA, Boon NA, Webb DJ: An in vivo model for the assessment of acute fibrinolytic capacity of the endothelium. Thromb Haemost 1997, 78:1242-1248.

17. Kneale BJ, Chowienczyk PJ, Brett SE, Cockcroft JR, Ritter JM: Forearm vasoconstriction in response to noradrenaline and NG-monomethyl-Larginine in essential hypertension. Clin Sci (Lond) 1999, 97:277-282.

18. Wilkinson IB, Webb DJ: Venous occlusion plethysmography in cardiovascular research: methodology and clinical applications. Br J Clin Pharmacol 2001, 52:631-646.

19. Holvoet $\mathrm{P}$, Cleemput $H$, Collen D: Assay of human tissue-type plasminogen activator (t-PA) with an enzyme-linked immunosorbent assay (ELISA) based on three murine monoclonal antibodies to t-PA. Thromb Haemost 1985, 54:684-687.

20. Vanmolkot $\mathrm{FH}$, de Hoon $\mathrm{JN}$ : Reproducibility of forearm vasodilator response to intra-arterial infusion of calcitonin gene-related peptide assessed by venous occlusion plethysmography. Br J Clin Pharmacol 2005, 59:387-397.

21. Oliver JJ, Webb DJ, Newby DE: Stimulated tissue plasminogen activator release as a marker of endothelial function in humans. Arterioscler Thromb Vasc Biol 2005, 25:2470-2479.

22. Newby DE, Sciberras DG, Mendel CM, Gertz BJ, Boon NA, Webb DJ: Intraarterial substance $\mathrm{P}$ mediated vasodilatation in the human forearm: pharmacology, reproducibility and tolerability. Br J Clin Pharmacol 1997, 43:493-499.

23. D'Amico D, Ferraris A, Leone M, Catania A, Carlin A, Grazzi L, Bussone G: Increased plasma nitrites in migraine and cluster headache patients in interictal period: basal hyperactivity of L-arginine-NO pathway? Cephalalgia 2002, 22:33-36

24. Gallai V, Floridi A, Mazzotta G, Codini M, Tognoloni M, Vulcano MR, Sartori M, Russo S, Alberti A, Michele F, Sarchielli P: L-arginine/nitric oxide pathway activation in platelets of migraine patients with and without aura. Acta Neurol Scand 1996, 94:151-160.

25. Sarchielli P, Tognoloni M, Russo S, Vulcano MR, Feleppa M, Mala M, Sartori M, Gallai V: Variations in the platelet arginine/nitric oxide pathway during the ovarian cycle in females affected by menstrual migraine. Cephalalgia 1996, 16:468-475.

26. Napoli R, Guardasole V, Zarra E, Matarazzo M, D'Anna C, Sacca F, Affuso F, Cittadini A, Carrieri PB, Sacca L: Vascular smooth muscle cell dysfunction in patients with migraine. Neurology 2009, 72:2111-2114.

27. de Hoon JN, Smits P, Troost J, Struijker-Boudier HA, Van Bortel LM: Forearm vascular response to nitric oxide and calcitonin gene-related peptide: comparison between migraine patients and control subjects. Cephalalgia 2006, 26:56-63.

28. Edvinsson ML, Edvinsson L: Comparison of CGRP and NO responses in the human peripheral microcirculation of migraine and control subjects. Cephalalgia 2008, 28:563-566.

29. Yetkin E, Ozisik H, Ozcan C, Aksoy Y, Turhan H: Increased dilator response to nitrate and decreased flow-mediated dilatation in migraineurs. Headache 2007, 47:104-110.

30. Thomsen LL, Iversen HK, Brinck TA, Olesen J: Arterial supersensitivity to nitric oxide (nitroglycerin) in migraine sufferers. Cephalalgia 1993, 13:395-399.

31. Thomsen LL, Daugaard D, Iversen $\mathrm{H}$, Olesen J: Normal radial artery dilatation during reactive hyperaemia in migraine without aura. Endothelium 1996, 4:199-206.

32. Corretti MC, Anderson TJ, Benjamin EJ, Celermajer D, Charbonneau F, Creager MA, Deanfield J, Drexler H, Gerhard-Herman M, Herrington D, et al: 
Guidelines for the ultrasound assessment of endothelial-dependent flow-mediated vasodilation of the brachial artery: a report of the International Brachial Artery Reactivity Task Force. J Am Coll Cardiol 2002, 39:257-265.

33. Yetkin E, Ozisik H, Ozcan C, Aksoy Y, Turhan H: Decreased endotheliumdependent vasodilatation in patients with migraine: a new aspect to vascular pathophysiology of migraine. Coron Artery Dis 2006, 17:29-33.

34. Vanmolkot FH, Van Bortel LM, de Hoon JN: Altered arterial function in migraine of recent onset. Neurology 2007, 68:1563-1570

35. Silva FA, Rueda-Clausen CF, Silva SY, Zarruk JG, Guzman JC, Morillo CA, Vesga B, Pradilla G, Florez M, Lopez-Jaramillo P: Endothelial function in patients with migraine during the interictal period. Headache 2007, 47:45-51.

36. Crassard I, Conard J, Bousser MG: Migraine and haemostasis. Cephalalgia 2001, 21:630-636.

37. Tietjen GE, Herial NA, White L, Utley C, Kosmyna JM, Khuder SA: Migraine and biomarkers of endothelial activation in young women. Stroke 2009, 40:2977-2982

38. Stang PE, Carson AP, Rose KM, Mo J, Ephross SA, Shahar E, Szklo M: Headache, cerebrovascular symptoms, and stroke: the Atherosclerosis Risk in Communities Study. Neurology 2005, 64:1573-1577.

39. Anderson TJ, Uehata A, Gerhard MD, Meredith IT, Knab S, Delagrange D, Lieberman EH, Ganz P, Creager MA, Yeung AC, et al: Close relation of endothelial function in the human coronary and peripheral circulations. J Am Coll Cardiol 1995, 26:1235-1241.

\section{Pre-publication history}

The pre-publication history for this paper can be accessed here: http://www.biomedcentral.com/1471-2377/10/119/prepub

doi:10.1186/1471-2377-10-119

Cite this article as: Vanmolkot and de Hoon: Endothelial function in migraine: a cross-sectional study. BMC Neurology 2010 10:119.

\section{Submit your next manuscript to BioMed Central and take full advantage of:}

- Convenient online submission

- Thorough peer review

- No space constraints or color figure charges

- Immediate publication on acceptance

- Inclusion in PubMed, CAS, Scopus and Google Scholar

- Research which is freely available for redistribution

Submit your manuscript at www.biomedcentral.com/submit
Biomed Central 